\title{
Research on the Retransmit Intention of Negative Word-of-Mouth Based on Interpersonal Trust in Mobile Internet Community
}

\author{
Yinhua $\mathrm{Hu}^{*}$ and Hui Yang
}

Jiangxi University of Finance and Economics, Nanchang 335300, China

\begin{abstract}
In order to prolong life of wireless sensor network, a novel clustering routing algorithm in wireless sensor networks based on energy equalization to solve the "hot hole" problems in the clustering routing protocol. Firstly, the monitoring region is divided into circular area which base station is taken as the center, and the monitoring area is divided into multi-sectors, the nodes in blocks form a cluster, and then the cluster head is selected according to the node residual energy, and the corresponding cluster communication according to the dispersion coefficient of cluster head, finally, single hop and multi hop is used to communicate between and the simulation experiment to used to test performance of the algorithm. The results show that the proposed algorithm can effectively improve the network energy efficiency and achieve energy consumption balanced among nodes, so it can prolong life time of wireless sensor network.
\end{abstract}

Keywords: Distribution coefficient, energy-efficient, network life, WSN.

\section{INTRODUCTION}

With the widespread use of mobile Internet, the timeliness and mobility of mobile Internet complement the participation and sharing features of social media rightly. It has become common that people build relationships in the virtual networks and virtual communities based on mobile Internet are formed accordingly. For the ease of communication, close and extensive social network relevance, the mobile internet community plays an important role on the spread of brand reputation. Negative Internet word-of-mouth (IWOM) means various negative information delivered by consumers about their disappointed consumption experience and unsatisfied feelings with regard to companies or products through network communication. The spread mechanism of negative word-of-mouth in mobile Internet community is essentially based on the social network of online community members. The community members re-spread the negative word-ofmouth they received among their own social networks by copying, transferring, instant communicating, knowledge sharing and other means, which makes the negative IWOM snowball.

In the mobile Internet, the recipients' retransmit willingness of word-of-mouth determines the speed and the size of WOM's spreading in the network. The stronger the wishes of the recipients, the faster and the wider the WOM will be spread. On the contrary, the weak-willing recipients are likely to stop spreading or just spread to a small number of people. Consequently the willingness of retransmission is the core of IWOM spreading mechanism. Bansal and Voyer (2000) once pointed that the effect of IWOM on consumers are primarily brought about by interpersonal influence [1].
Since interpersonal influence can be measured by interpersonal trust perception, it is necessary to analyze the role of interpersonal trust played in the reputation redistribution, so as to explore the spreading mechanism of negative IWOM in mobile Internet community in depth.

\section{LITERATURE REVIEW AND MODEL CON- STRUCTION}

\subsection{Subject of Negative WOM in Mobile Internet Com- munity}

Negative word-of-mouth means "consumers tell others about their unsatisfied consumption experience or vilify the company or product during interpersonal communication" [2]. With the rapid development and widespread use of Internet, negative word-of-mouth mainly takes the form of negative IWOM, which means releasing negative information about disappointed consumption experience and unsatisfied feeling with some company or product through a variety of network channels, such as BBS, weblog and so on.

Compared with real-life word-of-mouth and normal internet WOM, the negative word-of-mouth under mobile Internet environment could be re-spread by the community members more actively, and its impact, including the depth and breadth will also be more pronounced. Overall, the negative word-of-mouth in mobile Internet community in this study means that consumers, as the subjects of WOM, spread negative information or evaluation about function of particular brand, product quality, and consumption experience with the form of knowledge sharing through mobile Internet communication platform.

IWOM is a communication process in essence, and the subjects of communication include the disseminators and the recipients of information. Therefore, in the mobile Internet community, the subjects of certain negative word-of-mouth 
are accordingly a collection of transmitters and receivers of brand reputation, and also refer to all the community members who voluntarily transfer and share the negative brand WOM. Each member of mobile Internet community is likely to be a complex blend of transmitter and recipient of negative word-of-mouth. With regard to a recipient, whether he can be called a transmitter depends on his willingness to further spread the word. In this study, the dimensions and measurements of subjects are discussed by focus groups and mainly referred from the communication theory, which points out the following dimensions, expertise of transmitter, the relationship strength between communicator and recipient and the recipients' trust tendencies.

\subsection{The Interpersonal Trust in Mobile Internet Commu- nity}

In the mobile Internet community, knowledge sharing, including brand reputation spreading, is the most important means of communication to maintain the community's existence and development, as well as establish and maintain interpersonal relationships, while interpersonal trust is the important motivation to retransmit the brand reputation. Therefore, the spreading mechanism of negative word-ofmouth in mobile Internet community lies in the trust relation between community members.

The trust is defined by Scholars from different perspective. Baier (1994) pointed that trust means "firmly believing and expecting the goodwill of credit receiver" [3]. McAllister (1995) defined trust as "the likelihood of action based on someone's words, behavior and decision" [4]. It is apparent that the perception of interpersonal trust reflects a psychological state of individual in nature, and trust primarily show their confidence in the capability, honesty and goodwill of the person being trusted. Therefore the features of both the credit provider and the credit receiver are the most important factors affecting the strength of interpersonal trust. Viewed from the results of trust, it is mainly presented as the tendency to take relevant action based on the subjective assessment of credibility. For the brand reputation in the online community, consumers' trust in the information providers and the information itself will directly affect their cognition to the brand, the purchase intention, re-spreading aspiration and behavior of negative word-of-mouth. Therefore, this study assumes that:

H1: The stronger the interpersonal trust of the recipients, the stronger their retransmit intention of negative IWOM.

Viewed from the features of subjects of negative WOM in mobile Internet community, firstly, the professional feature of communicators (credit provider) is confirmed to have a significant impact on the trust [5], which precisely explain the reasons why the opinion leaders in the online community always get high interpersonal trust. Moreover, the rumor diffusion theory points that the reliability of sources has a positive impact on the audience's re-spreading intention and behavior [6]. It is proved that the credibility of sources are mainly measured through expertise index, which shows providers' ability to send correct information and exhibit professional behavior perceived by the receivers [7], and it can be observed by product knowledge, consumption experience, purchase experience of communicators and so on. Therefore, this study assumes that:
$\mathrm{H} 2$ : The expertise of communicator will significantly and positively affect the interpersonal trust of IWOM recipients in mobile Internet community;

H3: The interpersonal trust plays a mediating effect between the expertise of communicators and the recipients' retransmit intention of negative IWOM.

Secondly, the trust propensity of recipient (credit provider) is an important antecedent of trust, the higher the trust propensity, the more likely he is to trust others. Smith (2002) found that the trust propensity positively affect the individuals' trust, when empirically studying the influence of recommended information on consumers' purchase decision in virtual communities [8]. Meanwhile, the people with high trust propensity tend to be more susceptible to information disseminators and perform similar behavior with them, thus redistribute negative word-of-mouth they received. Therefore, this study assumes that:

H4: The trust propensity of recipient will significantly and positively affect the interpersonal trust of IWOM recipient in mobile Internet community;

H5: The interpersonal trust plays a mediating effect between the trust propensity of recipient and their retransmit intention of negative IWOM.

Finally, the relation strength between communicators and recipients of information will significantly affect the interpersonal trust. According to the intensity of relationship between both sides of communication, strong links and weak links can be divided. Strong links reflect close friends, family members or relatives, while weak ones refer strangers or those just-knows, which is particularly apparent in the mobile Internet community. The recommendation of strong links has much greater impact on recipients' behaviors than weak ties. The closer the relationship between people, the more likely they are to trust each other, and retransmit the received information further. Therefore, this study assumes that:

H6: The relation strength of both sides of communication will significantly and positively affect the recipients' interpersonal trust in mobile internet community;

H7: The interpersonal trust plays a mediating effect between the relationship strength and the recipients' retransmit intention of negative IWOM.

\subsection{The Model Construction}

According to the literature research, this study establishes a research model on negative IWOM retransmit willingness based on interpersonal trust in mobile Internet community (see Fig. 1)

\section{RESEARCH METHODS}

\subsection{Variable Measurement}

In this study, the questionnaire is used to measure the following 5 variables: the expertise of communicators, the trust propensity of recipients, the relation strength of both sides, the interpersonal trust and the retransmit intention. There are 18 observed items altogether and all are used Likert scale 5 to measure. For the measurements of "the 


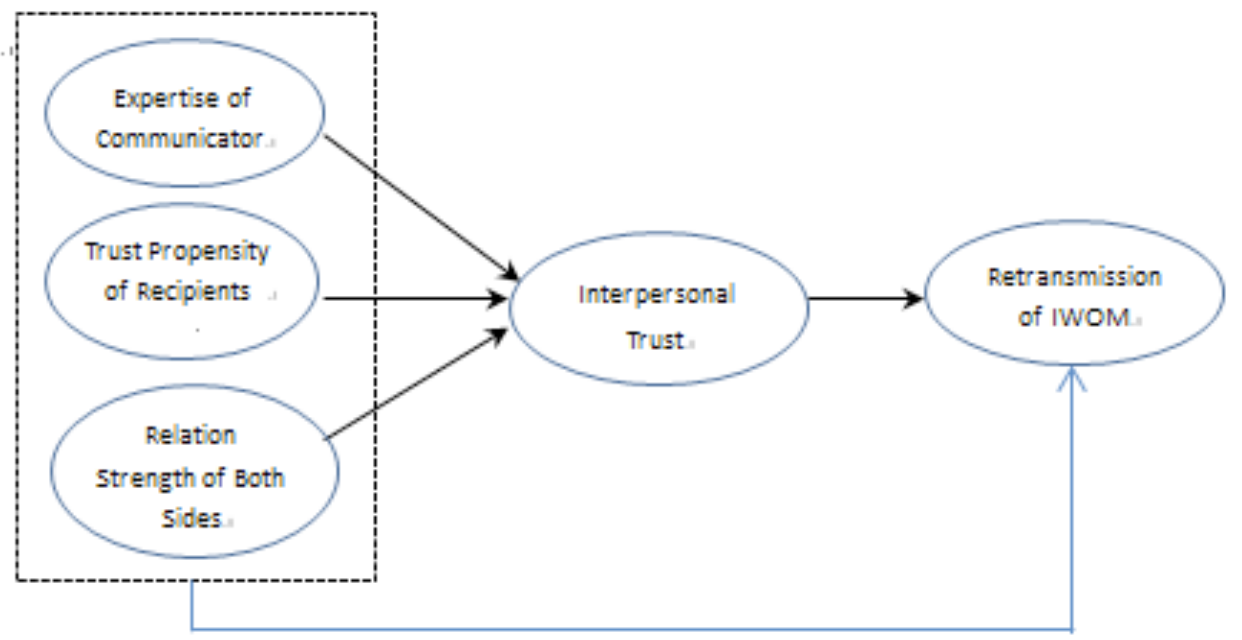

Fig. (1). Research model.

expertise of communicators", this study refers to the scale of "professional capability" by Gilly(1998), Bansal \& Voyer (2000), and designs three questions. For the scales of "trust propensity of recipient", this paper borrows the study of Lee \& Turban (2001), Ridings et al. (2002), and designs four items. The measurements of "relationship strength" in this study are based on the scales proposed by Frenzen \& Davis (1990), Gilly et al. (1998), including four dimensions: familiarity, intimacy, level of support and relevance. The measures of "interpersonal trust" are mainly referred from the achievement of Mayer et al. (1995), Ridings (2002), and made some modification. For the measurements of retransmit intention of IWOM, this study borrows the research by Brown et al. (2005) and Sun et al. (2006), and combines network platform to design the scales of online and offline re-spread willingness of negative IWOM, with four questions included.

\subsection{Data Collection}

This study aims at users of mobile Internet as the respondents. Since the mobile Internet users are always those who are young, fashionable, keen to Internet so long as available, fond of online shopping and aware of kinds of brand, this study selects highly educated groups as the main respondents and targets at their brand-sharing behaviors conducted in those popular mobile Internet community with a large amount of users, such as mobile QQ, mobile wechat and so on. It takes the form of online and offline questionnaire survey to obtain first-hand data. 412 questionnaires are distributed and 378 valid ones are returned in the survey, thus the response rate reaches $91.7 \%$.

\section{ANALYSIS AND RESULTS}

\subsection{Reliability and Validity Analysis}

In this study, the Cronbach's $\alpha$, a common indicator of internal consistency, is used to measure reliability of the scale. It is showed that the coefficient $\alpha$ of the overall scale is 0.780 and higher than the standard 0.7 , which indicates this scale has sufficient reliability. The Cronbach's $\alpha$ of five latent variables in the model are all in the range 0.650-0.749 and higher than the critical value 0.6 , while no variable significantly improve their reliability if some items are deleted, so excellent internal consistency of these latent variables is proved. The validity of the scale is primarily measured through the factor loadings of each item on the corresponding variable. This study uses software AMOS18.0 to conduct the confirmatory factor analysis and finds almost all the standardized regression weights of the items on each latent variable are greater than 0.5 , only two items' factor loadings are slightly low but still close to the critical value 0.5 . Moreover, among the 18 estimated parameters, except the 5 fixed parameters, all the estimated parameters reaches the significance level $(\mathrm{T}>3.3, \mathrm{P}<0.001)$, meanwhile, the standard errors of all the estimated parameters except the fixed ones are very small and no negative error variance emerges, which indicates. good internal quality of the model and good convergent validity of the scale. Specific results are shown in Table 1.

\subsection{The Hypothesis Test and Results}

\subsubsection{Regression Analysis of the Communicators' Charac- teristics and the Recipients' Interpersonal Trust}

Firstly, we take the interpersonal trust as the dependent variable, and the expertise of communicators, the trust propensity of recipients, the relation strength of both sides as the independent variables, to confirm their significant correlation respectively by multiple linear regression analysis. It is found that the highest value of variance inflation factor (VIF) of each independent variable is 1.058 , far less than 10 , and the minimum value of the tolerance is 0.945 , higher than the conventional boundary 0.1 , which indicate that there is no serious collinear problem among independent variables. The statistic of D.W is 1.915 and close to 2, so the basically independent residuals are proved and the prerequisites of multiple regression analysis is fulfilled. The significance is 0.000 and indicates that the regression model is statistically significant. Specific results are shown in Table 2.

With the regression analysis, the expertise of communicator of negative reputation in the mobile Internet community is proved to have a significant positive impact on the 
Table 1. The reliability and the convergent validity of latent variables.

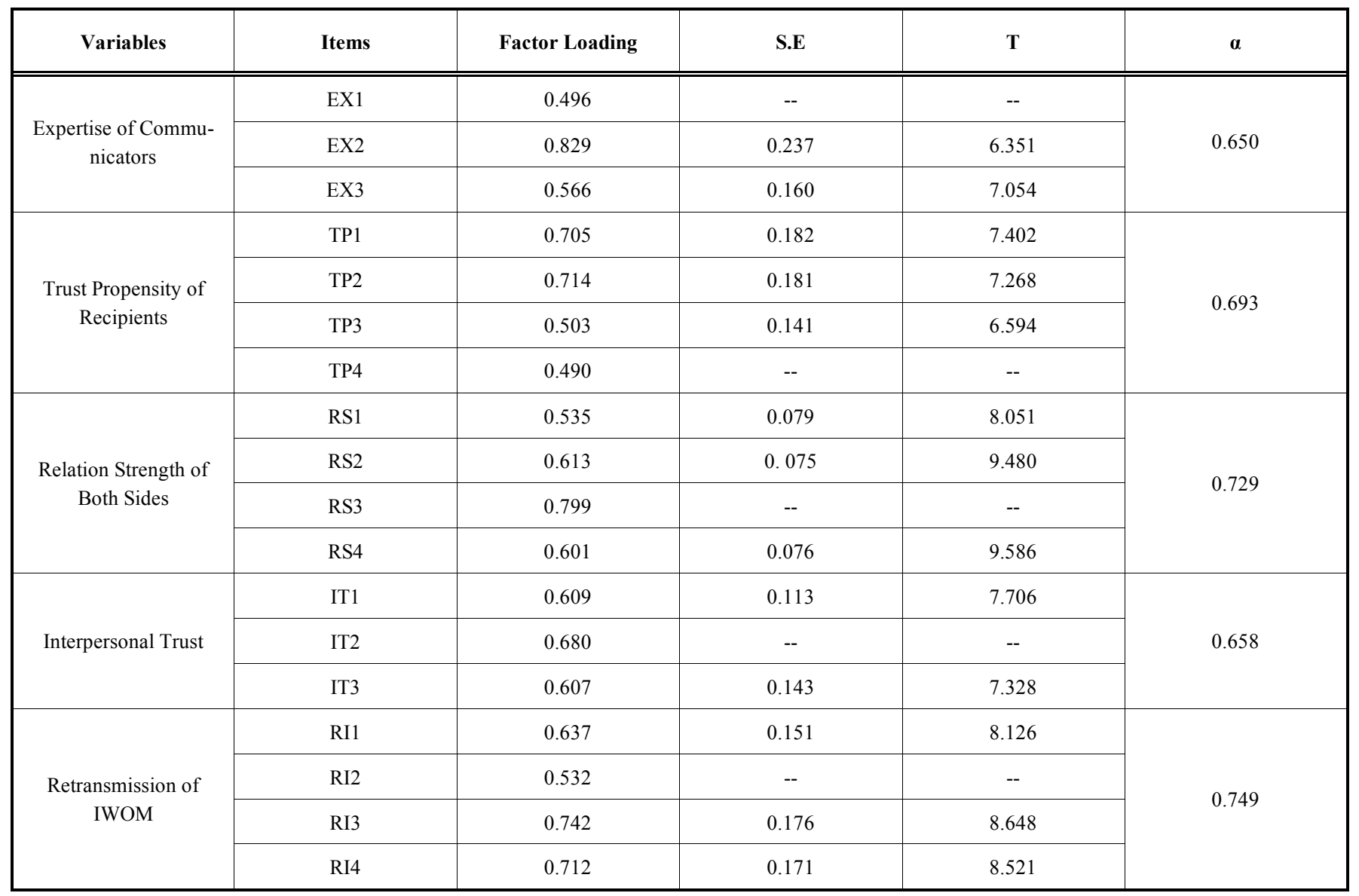

Table 2. Regression analysis of the communicators' characteristics and the recipients' interpersonal trust.

\begin{tabular}{|c|c|c|c|c|c|c|c|c|c|c|c|}
\hline Model & $\begin{array}{l}\text { Unstandardized } \\
\text { Coefficients }\end{array}$ & $\begin{array}{l}\text { Std. } \\
\text { Error }\end{array}$ & $\begin{array}{c}\text { Standardized } \\
\text { Coefficients }\end{array}$ & Sig. & Tolerance & VIF & $\mathbf{R}^{2}$ & $\begin{array}{c}\text { Adjusted } \\
\mathbf{R}^{2}\end{array}$ & $\mathbf{F}$ & Sig. & D.W \\
\hline Constant & 1.336 & 0.220 & & 0.000 & & & \multirow{4}{*}{$\begin{array}{c}0.11 \\
7\end{array}$} & \multirow{4}{*}{0.109} & \multirow{4}{*}{16.450} & \multirow{4}{*}{0.000} & \multirow{4}{*}{1.915} \\
\hline EX & 0.102 & 0.049 & 0.103 & 0.040 & 0.945 & 1.058 & & & & & \\
\hline $\mathrm{TP}$ & 0.217 & 0.053 & 0.202 & 0.000 & 0.960 & 1.042 & & & & & \\
\hline RS & 0.208 & 0.048 & 0.215 & 0.000 & 0.981 & 1.020 & & & & & \\
\hline
\end{tabular}

interpersonal trust of recipient $(\beta=0.103, \mathrm{P}<0.05)$, so the assumption 2 is verified. The trust propensity of recipient in mobile Internet community has a prominent influence on his own interpersonal trust $(\beta=0.202, \mathrm{P}<0.001)$, thus the hypothesis 4 is supported. The relation strength between the communicator and the receiver has an obvious effect on the interpersonal trust of recipient $(\beta=0.215, \mathrm{P}<0.001)$, and the supposition 6 is proved.

\subsubsection{Regression Analysis of Interpersonal Trust and Will- ingness to Re-spread Negative IWOM}

This study take the interpersonal trust as the independent variable and the retransmission of negative word-of-mouth as the dependent variable, to confirm the significant correlation of interpersonal trust and redistribution willingness by linear regression analysis. Specific results are shown in Table 3 .

As shown in Table 3, the regression model is statistically significant (Sig. $=0.000$ ), and the interpersonal trust of recipient in mobile Internet community has a significant positive impact on retransmit intention of negative word-of-mouth $(\beta=0.301, P<0.001)$, so the assumption 1 is supported.

\subsubsection{Mediating Effect of the Interpersonal Trust}

To further understand the role of interpersonal trust in the mobile Internet community on the re-spreading of negative word-of-mouth, this study tends to explore the mediating effect of the interpersonal trust. According the method of mediating effect test proposed by Z.L. Wen et al. (2004), this 
Table 3. Regression analysis of interpersonal trust and willingness to re-spread negative word-of-mouth.

\begin{tabular}{|c|c|c|c|c|c|c|c|c|c|}
\hline Model & $\begin{array}{c}\text { Unstandardized } \\
\text { Coefficient }\end{array}$ & $\begin{array}{c}\text { Std. } \\
\text { Error }\end{array}$ & $\begin{array}{c}\text { Standardized } \\
\text { Coefficient }\end{array}$ & Sig. & $\mathbf{R}^{2}$ & $\begin{array}{c}\text { Adjusted } \\
\mathbf{R}^{2}\end{array}$ & F & Sig. \\
\hline \hline Constant & 1.926 & 0.152 & & 0.000 & & & \\
$\begin{array}{c}\text { Interpersona } \\
\text { 1 Trust }\end{array}$ & 0.318 & 0.052 & 0.301 & 0.000 & 0.090 & 0.088 & 37.347 & 0.000 \\
\hline
\end{tabular}

Table 4. Analysis of mediating effect.

\begin{tabular}{|c|c|c|c|}
\hline \multirow{2}{*}{ Variables } & Model 1 & Model 2 & Model 3 \\
\cline { 2 - 4 } & Retransmission of Negative IWOM & Interpersonal Trust & Retransmission of Negative IWOM \\
\hline \hline Expertise of Communicator & $0.097^{*}$ & $0.103^{*}$ & 0.078 \\
\hline Trust Propensity & $0.186^{* * *}$ & $0.202^{* * *}$ & $0.150^{* *}$ \\
\hline Relation Strength & $0.348^{* * *}$ & $0.215^{* * *}$ & $0.310^{* * *}$ \\
\hline Interpersonal Trust & & & $0.178^{* * *}$ \\
\hline$\Delta \mathrm{R}^{2}$ & 0.188 & 0.117 & 0.216 \\
\hline$\Delta \mathrm{F}$ & $28.927^{* * *}$ & $16.450^{* * *}$ & $25.721^{* * *}$ \\
\hline
\end{tabular}

Note: $* \mathrm{P}<0.05, * * \mathrm{P}<0.005, * * * \mathrm{P}<0.001$ (two tailed)

study conduct a regression analysis with three steps to verify the standardized coefficients and their significance of each variable.

In the first step, it takes the retransmit intention of negative word-of-mouth as the dependent variable, as well as the expertise of communicator, the trust propensity of recipient and the relation strength as the independent variables, to verify the correlation between each variable by multiple linear regression analysis. Concrete results are shown in the model 1 of Table 4. As what are shown in Table 4, the expertise of communicator, the trust propensity of recipient and the relation strength all have significant correlation with retransmission of IWOM.

In the second step, the interpersonal trust is seen as the dependent variable, while the expertise of communicator, the trust propensity of recipient and the relation strength are viewed as the independent variables, and then a multiple linear regression analysis is used to get the model 2 in Table 4. It is found that the results are the same with that in Table 2, which means the characteristics of the subject of negative word-of-mouth are significantly associated with interpersonal trust.

In the third step, the retransmit intention of negative word-of-mouth is seen as the dependent variable, while the expertise of communicator, the trust propensity of recipient and the relation strength, as well as the interpersonal trust, are taken as the independent variables, and then a multiple linear regression analysis is used to get the model 3 in Table 4. From the results, it is shown that the standardized coefficients of interpersonal trust on the retransmission wishes of IWOM remains significant $(\beta=0.178, \mathrm{P}<0.001)$. By comparing the results of model 3 and model 1 , the standardized coefficients of the expertise of communicator, the trust propensity of recipient and the relationship strength are all declined after being joined the mediating variable, interpersonal trust. Thus it shows that the interpersonal trust plays an intermediary role in the influence of feature variables of negative IWOM subject on the retransmission wishes of recipients, thus assumption 3, 5, 7 are verified. Furthermore, among the feature variables of subjects of negative IWOM, the standardized coefficient of the expertise feature is not significant, and those of trust propensity and relationship strength are both significant, so it indicates that the interpersonal trust plays a complete mediating effect between the expertise feature and the retransmit intention of recipient, while a partial mediating effect between trust propensity and retransmission intention, as well as the relation strength and retransmit intention.

Judged from the degree of the mediating effect, the mediating effect of interpersonal trust between the expertise of communicators and the retransmission of IWOM is 0.018 $(0.103 * 0.178)$, and the one between the trust propensity and the retransmission of IWOM is $0.036(0.202 * 0.178)$, while that between the relation strength and the retransmission of IWOM is $0.038(0.215 * 0.178)$, so it is easily found that, among various characteristic variables, the relationship strength will bring about most interpersonal trust, followed is the trust propensity, and the least is the expertise feature. Combined with the total effect, the greater the mediating effect interpersonal trust plays in the re-spread of IWOM in mobile Internet community, the greater the total effect of independent variables on redistribution of IWOM. The results are shown in Table 4

\section{CONCLUSIONS AND RECOMMENDATIONS}

\subsection{Conclusion}

1. In the mobile Internet community, the relationship strength between communicator and recipient has a signifi- 
cant positive impact on the re-spread of negative IWOM, and is the most important factor of the re-spread of word-ofmouth. During the influencing process, interpersonal trust plays an important intermediary role. That is mainly because, the maintaining of interpersonal relationship is largely manifested in information sharing in the mobile Internet community, and people like to express their supports to the information disseminators by the way of "praise", "information review", "information transfer" and so on, and they also tend to pay more attention to the information shared by their intimate friends.

2. In the mobile Internet community, the trust propensity of recipient is an important factor affecting their willingness to further spread the negative word-of-mouth. In the influencing process, interpersonal trust is also an important mediating variable. That further validates the trust propensity is the important antecedents of trust, and it is such a stable variable that will not change with the change of the environment, whether in the real environment or in the virtual environment. In the mobile Internet community, the characteristics of trust tendency of the recipients will significantly affect their trust to the communicator, and then exhibit them homogeneity with the trusted parties on the behavioral tendencies, that is re-transmitting the received negative wordof-mouth.

3. In the mobile Internet community, the expertise of communicators also significantly affect the re-spread willing of the recipient of negative IWOM, but the effect is mainly focused on the intermediary role on account of interpersonal trust. That is to say, the expertise of communicator has no direct effect on the retransmit intention of word-of-mouth in nature, but it will affect that only if the recipients perceive the interpersonal trust to communicators, so the interpersonal trust plays a full mediating role in this process.

\subsection{Recommendation}

Viewed from the conclusions above, for the businesses, the most importance is to build their own brand by operating the manipulative factors, such as quality, performance, service, innovation, marketing, image and so on, as well as raise the consumers' consumption experience to promote the formation of positive word-of-mouth and reduce negative wordof-mouth. Secondly, companies should establish and effectively use the network platform to communicate with consumers, for example, establishing virtual brand communities, and encourage consumers to provide feedback about their "unsatisfactory" mood to the enterprise positively. Thus the consumers' sense of belonging to the brand community will be enhanced and their brand loyalty will be increased accordingly. Thirdly, enterprises should strengthen the management of the existing negative IWOM and take it as a regular management activity. They should survey the source of the negative reputation and grasp the original reasons why it is formed and properly addressed them. Finally, companies should take advantage of the interpersonal relationships in mobile Internet community, to share and disseminate timely information about the brand, such as promoting new products, adopting new technology, conducting corporate social responsibility and so on, so as to expand the brand awareness and influence among the mobile Internet users.

\section{CONFLICT OF INTEREST}

The authors confirm that this article content has no conflict of interest.

\section{ACKNOWLEDGEMENTS}

2014 Humanities and Social Sciences Project in Jiangxi(project number: GL1401); 2014 Innovation Fund for postgraduate student in Jiangxi (project number: YC2014B037).

\section{REFERENCES}

[1] H.S. Bansal, and P.A. Voyer, "Word-of-mouth processes within a services purchase decision context," Journal of Service Research, vol. 3, no. 2, pp. 166-167, 2000.

[2] M. L. Richins, "Word of mouth communication a negative information," Advances in Consumer Researeh, vol. 11, no. 1, pp. $697-$ 702, 1984.

[3] A.C. Baier, "Moral Prejudices:Essays on ethics," Cambridge: Harvard University Press, 1994.

[4] D.J. McAllister, "Affect-and cognition-based trust as foundations for interpersonal cooperation in organizations," Academy of Management Journal, vol. 38, no.1, pp. 24-59, 1995.

[5] Y. P. Chang, X. J. Liu, J. Yan, and J. L. Zhang, "Research on knowledge sharing in virtual communities on consumer purchase intention," Journal of Management Sciences in China, no. 4, pp. 86-96, 2011.

[6] R. L. Rosnow, J. L. Esposito, and L. Gibney, "Factors influencing rumor spreading: replication and extension," Language and Communication, vol. 8, no. 1, pp. 29-42, 1988.

[7] J. M. Bristor, "Enhanced explanations of word of mouth communication," The Power of Relationships, Research in Consumer Behavior, vol. 4, pp. 51-83, 1990.

[8] D.N. Smith, "Trust Me, Would I Steer You Wrong? The Influence of Peer Recommendations With in Virtual Communities," University of Illinois at Chieago, 2002.

\author{
Received: June 10,2015 Revised: July 29, 2015 Accepted: August 15, 2015 \\ (C) Hu and Yang; Licensee Bentham Open.
}

This is an open access article licensed under the terms of the (https://creativecommons.org/licenses/by/4.0/legalcode), which permits unrestricted, noncommercial use, distribution and reproduction in any medium, provided the work is properly cited. 